\title{
MONODRAMA: PRIMEIRAS IMPRESSÕES DO ABSURDO
}

\author{
Joana Prada SILVÉRIO ${ }^{40}$
}

AZEVEDO, C. Monodrama. Rio de Janeiro: 7Letras, 2009. 156 p.

$\underline{\text { Apresentação }}$

\author{
A foto do santuário de \\ Delfos \\ no Édipo de Pasolini \\ colada no painel do seu \\ carro \\ no espelho do banheiro \\ e na caixa de remédios \\ me repete \\ que você não é menos triste \\ do que qualquer pessoa \\ que eu conheça \\ nesta cidade \\ de imigrantes \\ fantasmas \\ à sombra do \\ obsessor
}

Carlito Azevedo

Carlos Eduardo Barbosa Azevedo, o poeta Carlito Azevedo, nasceu em 1961, na Ilha do Governador - Rio de Janeiro. Formado em Letras pela UFRJ, publicou seu primeiro livro de poemas, Collapsus Linguae, em 1991, tendo recebido o prêmio Jabuti. Além dele, saíram também As banhistas (1993), Sob a noite física (1996), Versos de circunstância (2001) e a antologia Sublunar (1991-2001). Monodrama, publicado em 2009, vem pôr fim a um silêncio de oito anos, em que a morte da mãe corroborou para o desencadeamento de uma crise na atividade de escrever:

A minha crise particular ocorreu quando me dei conta de como era obsceno trocar a própria dor por poesia. Trocar os seus pesares, como dizia Drummond, por contentamento de escrever. Passei a achar

\footnotetext{
${ }^{40}$ Mestranda. Programa de Pós-Graduação em Estudos Literários, Faculdade de Ciências e Letras, Universidade Estadual Paulista, UNESP, campus de Araraquara, CEP 14800-901, Araraquara, SP, Brasil - joana.psilverio@ig.com.br
} 
imoral escrever versos sobre milhões de mortos nos campos de concentração, e inútil falar sobre a cerejeira em flor. Mas ao mesmo tempo ia buscá-los, uns e outros, nas mais remotas antologias, e os aprendia de cor. Achei que só ia voltar a escrever quando passasse essa crise, cujos motivos pessoais não cabe tratar aqui, mas percebi que não adiantava esperar uma situação confortável para escrever, que ela nunca viria, que a crise era definitiva, como um contorno espiritual. Que eu estaria sempre desconfortável com a poesia e que só me restava, para ser honesto comigo mesmo, escrever as notícias dessa crise, num formato que talvez nem fosse mais necessário chamar de poemas, e sim de outra coisa qualquer, como notas da ruína. 'Monodrama' é, em certo sentido, mais composto de notas da ruína do que de poemas. (AZEVEDO; FREITAS, 2010).

Considerado por alguns como um poeta da geração 90, Azevedo desenvolveu um estilo muito próprio de encarar a produção poética contemporânea, que possibilita misturar uma infinidade de referências sem a preocupação de hierarquizá-las. Reconhecidamente um herdeiro dos concretistas, o poeta também tem a poesia marginal entre suas influências. $\mathrm{O}$ que permite tendências tão díspares de confluir numa mesma criatura é a capacidade de pensar tudo sob um núcleo polarizador de tensões. Como se faz ver em "Uma tentativa de retratá-la: [...] Mas o século 21 preservou / ainda as bibliotecas / sistema de / sistemas que nos permite pressupor / que em sua bolsa convivam, / como dois faunos se encarando, / Lancôme e La Celestina" (AZEVEDO, 2009, p.51). O exercício formal dessa habilidade é o que veremos então, nesta "tentativa" de resenha.

\section{$\underline{\text { O livro }}$}

O Monodrama plurivocal, de Carlito Azevedo, encena uma subjetividade fragmentária com a qual coexistem personagens como o imigrante, o ator, o confeiteiro, o estrangeiro, diversas figuras femininas e o anjo boxeador - a mais emblemática aparição do livro, para usar o título do primeiro poema como adjetivação dessa figura. Abrigando essa quantidade de caracteres está a cidade, que funciona como palco para o espetáculo do absurdo. Contudo, se é possível ver e ouvir as muitas vozes e faces que emanam desse teatro poético, também é preciso ter em conta um entendimento sobre o tipo de encenação expressa pela forma monodramática. Pavis (2008, p.246-247 apud EVREINOFF, 1930), aponta tratar-se de "um tipo de representação dramática na qual o mundo que rodeia a personagem aparece tal e qual a personagem o vê em todo 
momento de sua existência cênica". A tensão manifestada por essa construção dá a medida da complexidade do olhar moderno, que faz questão de referenciar todas as experiências ao seu ponto de vista, assumindo com isso uma postura altamente consciente, uma vez que opera com a admissão da subjetividade. Porém, a aparente centralidade desse sujeito explode em inúmeras perspectivas e o mundo se apresenta como profusão caótica de signos, ou ainda, como "imagens da pura / desconexão" (AZEVEDO, 2009, p.11).

O poema de abertura, "Emblemas", reúne 35 estilhaços de versos, acrescidos de um bônus track, em que se cria uma ambiência do cotidiano moderno, que permite a presença simultânea de uma manifestação em frente a um banco e a ereção do segurança que está ali para contê-la. Assim, sob este título, cunham-se diferentes matizes do mundo. Há então, no livro de Azevedo, uma pluralidade de vozes que se dá, não só no plano formal do tipo gráfico - vide as aspas, os itálicos e os dois pontos introdutórios em poemas como "O tubo", "Conto da galinha" e "Dois estrangeiros" -, mas também por meio de uma sintaxe supressora de qualquer encadeamento lógico: "Uns olhos negros / que vi na Turquia / reaparecem / no rosto / do novo inquilino / para água quente / basta girar este / disco de cores até / o rubro / o incandescente." (p.14). Neste trecho do poema, os dez versos-fragmentos podem ser divididos em dois blocos iguais. Assim, a voz que enuncia a constatação presente na primeira parte transmuta-se em uma personagem representando a si mesma, dando as indicações para o inquilino dos olhos turcos. A quebra sintática de ordenamento é o que denuncia, através da preposição "para", a intromissão de uma voz diversa da que fala a princípio, configurando uma espécie de discurso indireto livre poético, em que a projeção de uma personagem sobrepõe-se ao sujeito lírico. Essa criatura cindida entre observações muito particulares e a expressão delas domina todo o livro e manifesta-se como um entendimento da dicção moderna. A abrangência dessa dicção é tamanha que torna possível ouvir a pressuposta pergunta do inquilino. A fala desta personagem não está posta no poema, nem mesmo o questionamento aparece; contudo, a informação dada cria uma retomada de relações, em que a voz da representação do sujeito lírico assenhora-se do entorno.

Em "O tubo", poema dividido em três partes - "Paraíso", "Purgatório" e "Inferno" -, um passeio também serve para que essa personagem monodramática, que tudo vê e fala, expresse sua existência solitária. Numa espécie de diálogo de surdos, 
temos a representação do sujeito lírico pedindo ao seu interlocutor que retome uma ideia lançada anteriormente, que havia se perdido talvez, por conta de uma distração. Mas, para que isso aconteça, seria necessária a cessão do turno de fala, o que não ocorre. Ao invés disso, cada nova abertura do discurso vem com a seguinte introdução: "eu disse". Assim, apesar da presença de um interlocutor, apenas o sujeito lírico, como projeção de si, aparece vendo e dizendo aquilo que caberia ao outro. Nos momentos em que as aspas remetem para uma fala distinta da dessa personagem dominadora, fica sempre evidente que foi sob seu olhar que ela foi filtrada. Como ele mesmo reconhece: "eu disse: eu preciso / lhe dizer o que gravei / como sendo o que / aproximadamente / você disse, / mas é claro que / não vai ser o / que realmente você / disse, é apenas / uma adaptação / e que por isso / mesmo só pode existir / embaciando a / informação original, / só se dará como pálida / sombra da coisa / em si brilhante e luminosa: / o seu objeto singular." (AZEVEDO, 2009, p.40, grifo do autor).

Discutindo a construção da figuratividade, na obra de Azevedo, Flora Süssekind (2008) convoca o drama de estação - definido, por Szondi (2001), na perspectiva de um eu central - como possível indicação de leitura. Assim, falando sobre o poema "Margens", além de reconhecer o que chama de "teatralidade relutante", Süssekind também aponta para o desenvolvimento concomitante de uma técnica narrativa: o poema percurso. Por ela, podemos pensar um processo de composição que dilui a condensação imagética num trânsito visual. Para Süssekind (2008, p.64), no lugar de “imagens-síntese”, temos "imagens-em-sucessão que se desdobram, por vezes sem maiores analogias, umas das outras".

A essa despreocupação analógica, ou ainda, a pouca importância dada em estabelecer vínculos lógicos entre as partes, podemos associar a construção de uma figura como o anjo boxeador, que domina boa parte do livro, aparecendo nos seguintes poemas: "As metamorfoses", "Um confeiteiro da cidade de X... observa a foto do asteróide 433 Eros contra um fundo de estrelas num único pixel iluminado", "Handgun carryng case", "O anjo boxeador", "Café", "O anjo boxeador tenta descrever uma cena" e "O anjo foge". O investimento figurativo dessa personagem reside na junção de elementos díspares convivendo sob um mesmo epíteto. Tradicionalmente, o anjo é aquele que traz a mensagem divina e promove a ligação entre Deus e os homens. Contudo, a essa figura caracteristicamente espiritual, Azevedo associa a qualificação de 
boxeador. O choque promovido por essa união absurda realiza-se nos poemas por uma percepção temporal de instantes fugidios e mudanças tão bruscas no estado das coisas, que impossibilitam qualquer previsão de acontecimento. Não à-toa, dominam esses poemas imagens de explosões, mortes e doenças. $\mathrm{O}$ anjo boxeador aparece, então, como voz contrária, uma vez que, ao invés de anunciar as boas-novas, sua mensagem está repleta de desolação e caos.

\section{Considerações finais}

Matizado por várias vozes, encenadas sob a perspectiva de um sujeito, que também se quer personagem de si mesmo, Monodrama dá espaço para o cotidiano moderno representado em sua mais latente característica: a contradição.

\section{REFERÊNCIAS}

AZEVEDO, C. Monodrama. Rio de Janeiro: 7Letras, 2009.

AZEVEDO, C.; FREITAS, G. Entrevista com Carlito Azevedo, autor de Monodrama. O Globo, Rio de Janeiro, 2 janeiro 2010. Disponível em http://www.oglobo.com.br/ Acesso em 5 abril 2011.

PAVIS, P. Dicionário de teatro. Tradução sob a direção de J. Guinsburg e Maria Lúcia Pereira. São Paulo: Perspectiva, 2008.

SÜSSEKIND, F. A imagem em estações - observações sobre 'Margens', de Carlito Azevedo. In: ALVES, I.; PEDROSA, C. (Org.). Subjetividades em devir: estudos de poesia moderna e contemporânea. Rio de Janeiro: 7Letras, 2008. p.63-81.

SZONDI, P. Teoria do drama moderno [1880-1950]. São Paulo: Cosac \& Naify, 2001. 